\title{
Evaluation of Breeding Substrates for Cocoa Pollinator, Forcipomyia spp. and Subsequent Implications for Yield in a Tropical Cocoa Production System
}

\author{
Michael Adjaloo ${ }^{1}$, Ben Kwaku Branoh Banful ${ }^{2}$, William Oduro ${ }^{3}$ \\ ${ }^{1}$ Technology Consultancy Centre, College of Engineering, KNUST, Kumasi, Ghana; ${ }^{2}$ Department of Horticulture, Faculty of Agri- \\ culture, College of Agriculture and Natural Resources, KNUST, Kumasi, Ghana; ${ }^{3}$ Department of Wildlife and Range Management, \\ Faculty of Renewable Natural Resources, College of Agriculture and Natural Resources, KNUST, Kumasi, Ghana. \\ Email: bproofa@gmail.com
}

Received November $26^{\text {th }}, 2012$; revised December $28^{\text {th }}$, 2012; accepted January $5^{\text {th }}, 2013$

\begin{abstract}
A comparative study was carried out to determine the most suitable substrate for breeding of midges (Forcipomyia spp.) and the implications for pollination and yield in a typical cocoa production system in the forest ecological zone of Ghana. For the field experiment, the typically available substrates in cocoa farms which were used as the treatments under cocoa trees were: 1) rotten cocoa leaf litter; 2) rotten cocoa pod husks; and 3) rotten banana pseudostem. The untreated cocoa trees served as control. The experiment was set up in a randomized complete block design with three replications. For the laboratory experiment, the design was completely randomized design with four replications. The objective was to determine which substrate best supported breeding of the midges. The rotten banana pseudostem substrate recorded the highest population (7680) of Forcipomyia spp. after 56 days of observation. The cocoa pod husk and cocoa leaf litter recorded populations of 5226 and 1920, respectively. Similar observations were recorded in the level of pollination of the cocoa trees treated with rotten banana pseudostem (95.78\%), cocoa pod husks (89.05\%) and cocoa leaf litter (68.42\%). Application of all substrates to the cocoa tree resulted in a 77\% mean reduction in flower abortion as compared to the control. Fruit abortion, on the other hand, was significantly greater in trees treated with rotten banana pseudostem (73.7\%) and rotten cocoa pod husks (71.3\%) than in trees treated with rotten cocoa leaf litter (54.3\%). Application of banana substrate explained $88 \%$ of the variation in cherelle production (fruit set) whereas cocoa pod husks and cocoa leaf litter accounted for $71 \%$ and $94 \%$, respectively, of the variation in cherelle production. The study concluded that although cocoa leaf litter resulted in average increases in midges population and subsequently not too high levels of pollination, there was a significantly higher number of set fruits retained which implied high cocoa pod yields. Consequently, in accordance with the observed trend cocoa leaf litter should be considered as the most appropriate substrate for midges activity in cocoa for high yields.
\end{abstract}

Keywords: Breeding; Cocoa; Pollinator; Substrates; Yield

\section{Introduction}

Ghana is the second highest producer of world cocoa with a tonnage of 1 million MT [1]. The cocoa sector alone employs over 80,000 small holder farm families [2], representing 19 percent of rural households, and contrib.uting between $70 \%$ - 100\% of annual household incomes of smallholder farmers [3]. Ghana's agricultural GDP attributed to cocoa increased from 13.7 percent in 20002004 to 18.9 percent in 2005/2006 [3]. To sustain such remarkable growth in production, there is the need to take a more critical look at the ecosystem to improve on the features of the system which have positive impact on cocoa yields [4]. Cocoa pollination has since 1925 been a subject of interest [5] and yet very little is known about the mechanisms of pollination that contribute to the production of the fruits and subsequently the yield of the tree [6]. Over the years, several workers have established that cocoa is entomophilous, dependent on cross-pollination, and the responsible insects are midges (Forcipomyia spp.) of the family Ceratopogonidae [7-15]. Moreover, [16] suspected that pollination of cocoa by insects was one extrinsic limiting factor regulating fruit set in cocoa. $[17,18]$ reported that over $90 \%$ of flowers produced by cocoa trees drop after opening. Consequently only $10 \%$ of the total flowers produced pollinate successfully. This low success percentage is even dependent on the activities of midges in the cocoa plantation. [19] observed that inadequate pollination of cocoa 
by midges in cocoa plantations occurred when rotten vegetation had been too fastidiously removed, and concluded that a knowledge of breeding sites could leverage to increase pollinator populations. [20] confirmed this assertion in Malaysia, where an increase in pollinator populations was observed when additional substrate of rotten palm trunks was provided on the cocoa farms These results provided the first demonstration that pollinator abundance was limited by a lack of breeding sites which ultimately affected fruit set and yield. They further confirmed the need to increase insect pollinator population especially at the time of the year when pollination was most needed through some cultural techniques that could enhance their population in cocoa farms and subsequently increase the level of pollination $[9,18,21]$. To date however, there is a dearth of information on midges' population dynamics and their effect on cocoa fruit yield in the cocoa producing areas. Additionally, no investigations have been conducted on substrates to determine their relative importance in relation to the midges' population dynamics in spite of the fact that several substrates including rotten cocoa pod husks, decomposing cocoa leaf litter, rotten banana stems and decaying logs are available in cocoa farms [9,21-23]. It is believed that the current production level of 1 million MT could be further increased if the most appropriate breeding substrate is determined and promoted in the cocoa farms to facilitate effective and efficient pollination. To this end therefore, a comparative study was carried out to determine the most suitable substrate for breeding by midges (Forcipomyia spp.) in typical cocoa farms in the forest ecological zone of Ghana. Specifically the study sought to:

1) Evaluate the ecological importance of the various breeding substrates in the cocoa production system;

2) Determine the substrate preference for breeding by the midges (Forcipomyia spp.) and yield implications of the preferred substrate.

\section{Materials and Methods}

\subsection{The Biophysical Characteristics of the Study Area}

The study location called Kubease in the Ejisu-Juaben District of the Ashanti Region of Ghana lies between latitudes $6^{\circ} 44^{\prime} \mathrm{N}$ and $6^{\circ} 40^{\prime} \mathrm{N}$ and longitudes $1^{\circ} 15^{\prime} \mathrm{W}$ and $1^{\circ} 22^{\prime} \mathrm{W}$ (source: Gold Coast Survey Field Sheet No.129, Scale 1:62,500), and it is about 180 to $240 \mathrm{~m}$ above sea level. The natural forest belongs to the Trip-lochitonCeltis Association of the Tropical Moist Semi-Deciduous Formation [24]. The area has an annual average temperature of 26.5 ( \pm 2.09$)$ OC, relative humidity of $86.1 \%$ $( \pm 12.6 \%)$, and a mean monthly rainfall ranging between $19.1-235.1 \mathrm{~mm}$. The area experiences a bimodal rainfall distribution, with peaks in June and September. The first and second growing seasons typically last from midMarch to mid-July and from mid-August to end of November, respectively, separated by a short dry spell of about four weeks in July. The major dry season starts in mid-November and lasts till end of March. The climate is marked by high incidence of solar radiation and relatively little variation in day length.

\subsection{Field Procedure}

The study was conducted over two years (2008 and 2009) during the peak of two flowering seasons (June and July) using six farmer-managed cocoa farms purposively selected based largely on accessibility and willingness on the part of the farmers. No chemical inputs such as fertilizers herbicides were used in these selected farms, a practice which is typical for the area. The experiment was a randomized complete block design (RCBD) with four treatments and three replicates. In each farm, ten adult flower-bearing cocoa trees between 20 - 25 years, within a $400 \mathrm{~m}^{2}$ plot were randomly selected and tagged. For eight consecutive weeks ( from June to July) $160 \mathrm{~kg}$ (20 kg/tree/week) of rotten cocoa leaf-litter collected from different parts of the farm were placed in a wooden quadrat measuring $1 \mathrm{~m} \times 1 \mathrm{~m}$ around each of three randomly selected cocoa trees in each farm. Same mass of rotten banana pseudostem and rotten cocoa pod husks were collected and placed in wooden quadrats of same dimensions around each of three randomly selected cocoa trees. Three cocoa trees per farm were also left untreated to serve as the control. Thus, a total of 72 cocoa trees in six farm plots were used in the study. Fifty flowers per tree were labeled with a number tag that was attached by needle to the tree. Due to the fact that cocoa trees have a high flowering turnover new flowers were tagged every 3 to 4 days in order to maintain the total number of 3600 flowers. The relative importance of the substrates was evaluated using the following pre-maturity parameters of yield:

1) Flower set (an indication of successful pollination);

2) Fruit set before harvest (indicated by cherelle formation);

3) Fruit abortion, a premature loss of pollinated flowers (indicated by cherelle wilt).

The flower set was characterized by slight increase in purple coloration in the petals and sepals after 24 hours coupled with drying of the sepals which completed within 36 hours. Cherelle formation and aborted fruits (pod loss) were counted weekly for the eight weeks. The impact of the midges on cocoa pollination therefore, was determined by the number of targeted flowers that were pollinated as the substrates increased in quantities.

Although experimental and control plots were generally mixed together in the farms it was assumed that co- 
coa trees with greater densities of midges breeding beneath them have far greater fruit set because midges generally visit the flowers of nearby trees first, before moving to others [25]. Presumably, trees in control plots had less population of midges compared to those with substrates. A greater amount of pollinating activity resulting from an increased abundance of ceratopogonid midges was expected to be manifested in higher level of fruit set [25].

\subsection{Laboratory Procedure}

A laboratory experiment was conducted to determine which substrate supported the highest population of the midges. The design was completely randomized with four replications. Rotten cocoa husks, rotten cocoa leaves, and rotten banana pseudostem were collected in polythene bags from different parts of the study farms and sent to the laboratory. Rotten cocoa leaves (50 g), rotten cocoa husks (50 g) and rotten banana pseudo stem pieces (50 g) were homogenized separately with $50 \mathrm{ml}$ of water and the liquid extracts obtained by filtration through gauze.

Bioassay: Six emergence boxes measuring $20 \mathrm{~cm} \times 20$ $\mathrm{cm} \times 20 \mathrm{~cm}$ each with 4 circular holes $(\mathrm{d}=2 \mathrm{~cm})$ on the lid, were filled with $3 \mathrm{~kg}$ of a common rotten substrate i.e. cocoa pod husk. The boxes were subjected to the following treatments: $2 \mathrm{~g}$ of cotton wool was wetted with $1 \mathrm{ml}$ of the rotten cocoa leaves extract and packed tightly at the bottom of a test tube $(\mathrm{l}=150 \mathrm{~cm} ; \mathrm{d}=24 \mathrm{~cm})$. A second test tube was similarly treated and positioned directly opposite the first test tube. The third and fourth test tubes were also packed but with cotton wool wetted with distilled water to serve as controls. The four test tubes were placed upside down over the circular holes of the emergence box containing the substrate. An incandescent light was set about half a meter over and away from the box. Ten minutes after each flight observation, the test tube was removed while simultaneously covering the mouth of the test tube with cotton wool with chloroform, and the circular hole of the box with filter paper. Thus, only the midges found inside the test tube were recorded after each observation. For a total of 7 days in a month, the set-up was observed for 14 hours each day for three months. Hourly count $(06.00-08.30)$ of the number of midge flights towards the extract or water in the test tubes was done. The whole set-up was repeated using extracts of rotten cocoa pod husks and subsequently the rotten banana pseudo stem pieces. The number of midge flights per hour was used as an indication of which substrate extract attracted most midges.

A follow up experiment was conducted to determine which substrate harbored the most adult midges. The design was completely randomized design with four rep- lications. The six emergence boxes were divided equally among the three substrates. All the four test tubes per box were packed with cotton wool wetted with distilled water, and placed on the boxes as in the first study. An hourly count (06:00 - 18:00 h) of midge flights for 10 days per month for two months. Fresh substrates were used at the commencement of each 10-day observation, and were periodically moistened with distilled water to maintain the moist environment for the midges. The rate of flight per hour (i.e. average number of midges that emerged from the substrate per 15 minutes $\times 4$ ) observed in the test tube was a proxy indication of population of midges in the substrates.

\section{Data Analysis}

The field data were subjected to analysis of variance (ANOVA), using Statistix 8 software. Least significant differences (LSD) were calculated and the probability of treatment means being significantly different was set at $P$ $=0.05$. The number of flower sets, cherelles and aborted fruits were count data and therefore the data were square root $(\sqrt{X}+0.5)$ transformed before analysis was done. Regression analyses were performed to determine relationships between substrates and flower sets, cherelles and aborted fruits.

For the laboratory study, two sets of analysis were carried out after the data was square-root $(\sqrt{X}+0.5)$ transformed, to determine which of the substrates was most preferred for breeding. The first set of analysis was a series of t-tests to compare the attraction level of water and the substrate extracts. Since the base substrate cocoa pod husks, and the control, water were constant, the results would indicate which extract was preferable to the midges. The second set of analysis involved a one-way ANOVA of midges' emergence from the six boxes. The population was indirectly determined by the rate of midge flight per hour (i.e. average number of midges that emerged from the substrate per 10 minutes $\times 6$ ) from each substrate. All laboratory analysis was done using the SAS 9.0 (2005) version.

\section{Results}

\subsection{Midges' Preference of the Breeding Substrates}

In both field and laboratory studies, midges' populations were significantly $(\mathrm{P}<0.05)$ greater under rotten banana pseudostem than the other substrates. Indeed, the population of midges' was increased by $46.9 \%$ under the rotten banana pseudostem as compared to the cocoa pod husks and by $300 \%$ as compared to the cocoa leaf litter (Table 1). There was a strong and positive correlation $(r=0.95)$ between the weight of substrates and the midges popula- 
tion in the field.

There were significant differences $(\mathrm{P}<0.05)$ between the substrate types for flower set, flower abortion, fruit set and fruit abortion (Table 2). The mean number of flower set of the cocoa tree was significantly higher under the rotten banana pseudostem substrate than the others. Collectively, flower set under all the substrates were significantly greater than under the control. Flower set was also significantly higher under rotten cocoa pod husks as compared to rotten cocoa leaf litter. However, not all the set flowers became set fruits. There was significantly higher flower abortion under the control as compared to the substrate treated cocoa trees. Among the substrates, however, there were no significant differences in flower abortion. In fact application of substrate to the cocoa tree resulted in a $77 \%$ mean reduction in flower abortion as compared to the control. Fruit set was similar among cocoa trees treated with rotten banana pseudostem and rotten cocoa pod husks yet significantly greater than fruit set of cocoa trees treated with rotten cocoa leaf litter, the mean difference being $45 \%$. The control recorded the least mean number of fruit set (Table 2). Fruit abortion,

Table 1. Population of midges in different weights of rotten banana pseudostem, cocoa pod, and cocoa leaf litter.

\begin{tabular}{ccc}
\hline & \multicolumn{2}{c}{ Estimated midge population per } \\
\cline { 2 - 3 } & \multicolumn{2}{c}{ Substrate } \\
\hline $\begin{array}{c}\text { Substrate } \\
\text { Banana }\end{array}$ & $3 \mathrm{~kg}$ & $160 \mathrm{~kg}$ \\
pseudo stem & 144 & 7680 \\
Cocoa pod & & \\
Husk & 98 & 5226 \\
Cocoa leaf & & \\
litter & 36 & 1920 \\
Control & 27 & 1440 \\
LSD 5\% & 5.35 & 4.40 \\
\hline
\end{tabular}

Table 2. Effect of midges population as per substrates on flower set, flower abortion, fruit set and fruit abortion.

\begin{tabular}{ccccc}
\hline & \multicolumn{4}{c}{ Mean number of reproductive structures } \\
\cline { 2 - 5 } Substrate & Flower set & $\begin{array}{c}\text { Flower } \\
\text { abortion }\end{array}$ & Fruit set & $\begin{array}{c}\text { Fruit } \\
\text { abortion }\end{array}$ \\
\hline $\begin{array}{c}\text { Rotten banana } \\
\text { pseudostem }\end{array}$ & 95.8 & 11.2 & 85.1 & 62.7 \\
$\begin{array}{c}\text { Rotten cocoa } \\
\text { pod husks }\end{array}$ & 89.1 & 7.8 & 82.1 & 58.5 \\
$\begin{array}{c}\text { Rotten cocoa } \\
\text { leaf litter }\end{array}$ & 68.4 & 15.8 & 57.6 & 31.3 \\
Control & 50.0 & 43.4 & 21.7 & 20.1 \\
$\begin{array}{c}\text { LSD 5\% } \\
\text { RSD }\end{array}$ & 4.42 & 8.31 & 17.51 & 11.75 \\
\hline
\end{tabular}

on the other hand, was significantly greater in trees treated with rotten banana pseudostem (73.7\%) and rotten cocoa pod husks (71.3\%) than in trees treated with rotten cocoa leaf litter (54.3\%). The control (water treatment) lost $92.6 \%$ of fruit set through abortion (Table 2). Consequently, trees treated with rotten cocoa leaf litter retained the highest percentage fruit set of $46 \%$ of fruit set whiles cocoa trees treated with rotten banana pseudostem and trees treated with rotten cocoa pod husks retained about $26 \%$ and $29 \%$ of fruit set, respectively.

\subsection{Effect of Substrate Weight on Fruit Set and Fruit Abortion}

Figures 1-6 present the relationships between the increasing weight of substrate types and the resulting fruit set and aborted fruits. Substrate application was a better predictor of the rate of cherelle production (Fruit set) (Figures 1, 3 and 5) than for fruit abortion (Figures 2, 4 and 6). Application of banana substrate explained $88 \%$ of the variation in cherelle production whereas cocoa pod husks and cocoa leaf litter accounted for $71 \%$ and $94 \%$, respectively, of the variation in cherelle production. For fruit abortion however, substrate application was not a good predictor considering the lower $\mathrm{R}^{2}$ values, thus suggesting that other factors may also be involved in explaining the observed fruit abortion.

There was no significant inter-year difference in the

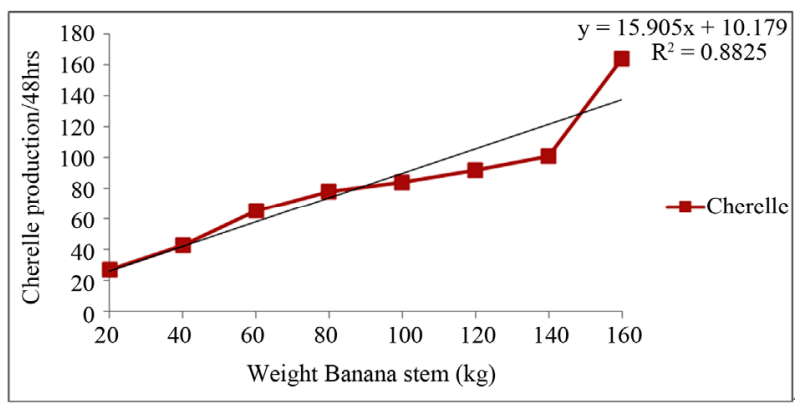

Figure 1. Rate of cherelle production under banana substrate treatment.

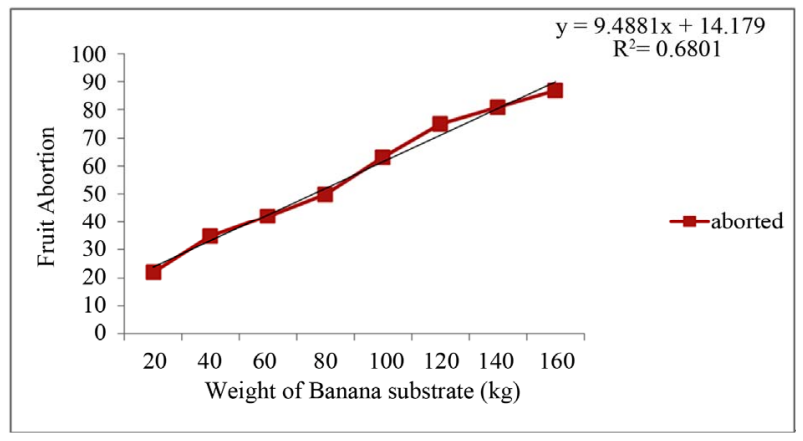

Figure 2. Rate of fruit abortion under banana pseudostem substrate 


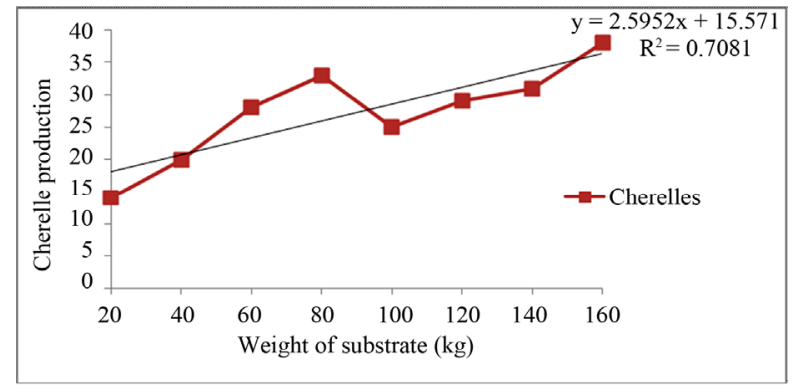

Figure 3. Rate of cherelle production under cocoa pod husk substrate.

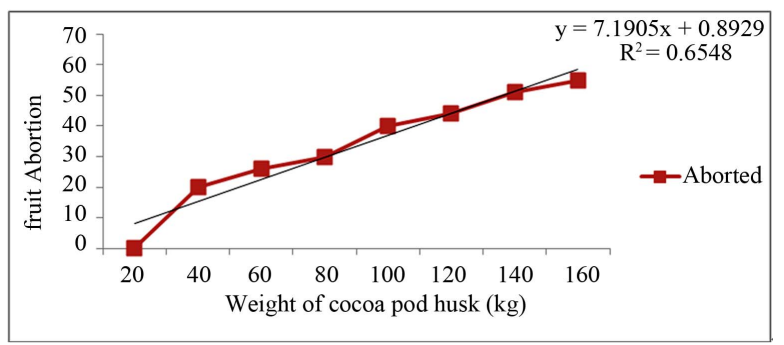

Figure 4. Rate of fruit abortion under the cocoa pod husk substrate.

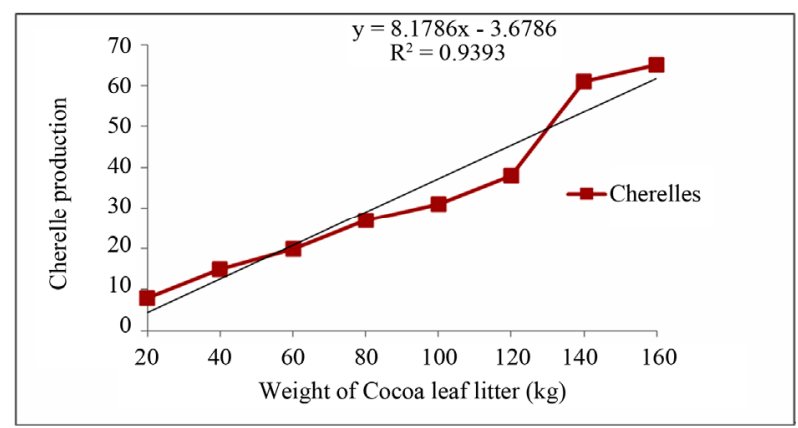

Figure 5. Rate of cherelle production under Cocoa leaf litter treatment.

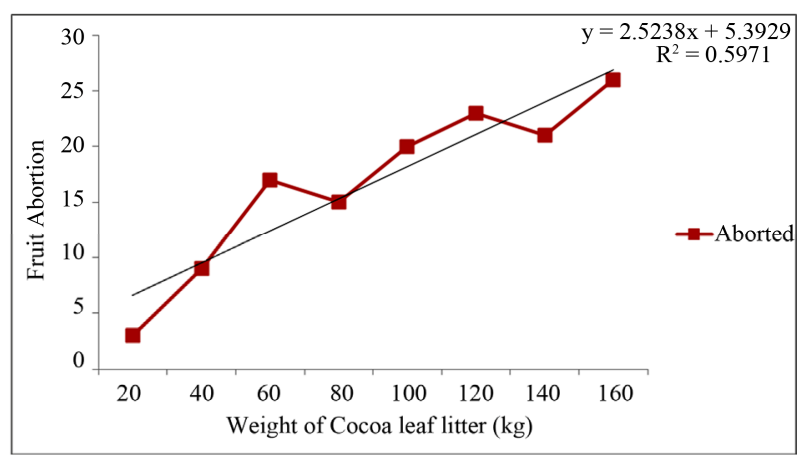

Figure 6. Rate of fruit abortion under cocoa leaf litter treatment.

fruit or seed set of the pollinated flowers. There was however significant difference in the fruit proportions produced between the different treatments $(t=1.82$; $\mathrm{df}=$
238; $p=0.05$ ), an indication that all the trees were not under the same pollinating conditions.

\section{Discussion}

\subsection{Midges' Population in the Breeding Substrates and Its Effect on Cocoa Pollination}

All the rotten substrates resulted in population increases in midges as compared to the water control. This supports [8] who indicated that cocoa pollinators depend on moist rotten plant material for breeding. The positive correlation found in the present study between the weight of the substrates and the midge population further proves the point that midges population tends to increase only when a lot of rotten plant material is available. This implies that cocoa farms should be such managed that rotten plant material would always be available to ensure effective pollination and subsequent high fruit yields. Increased fruit set on nearby trees was also observed when discs of rotten banana stems were added to the ground litter of a shaded cocoa farm [26]. On the contrary, [16] found rotten cocoa pods to be the best substrate with regard to midges species diversity and population. These contrasting observations therefore suggest that different species of midges may have different substrate preferences and as such any further studies on cocoa pollination as related to substrate should be given a more location-specific consideration. There were increases in pollination levels of cocoa flowers probably due to the higher rates of midges visits to the flowers resulting from the increased midges population arising from the increased substrate accumulation. $[27,28]$ also made similar observations. The increased pollination could also be explained in terms of the inverse relationship between the time pollinators spend searching for flowers and the population size of the pollinator. [29] indicated that the shorter the searching time the higher the pollination rate. In earlier studies, similar results were obtained by [30,31].

Substrates which produced more flower sets had less flower abortion. Flower abortion has been attributed to low pollination or a reduction in auxin level due to delayed pollination [32,33]. Given the fact that the pollinator population determined the pollination intensity, the flower abortion could be higher under the control conditions where the lowest pollinator population was registered.

\subsection{Impact of Substrates on Cherelles and Fruit Abortion}

The positive linear relationships between the substrates and the production of cherelles was indicative that the 
presence of the substrates enhanced both the visitation rate and pollinator importance of the Forcipomyia spp. This therefore suggested that the deliberate accumulation of rotten plant material under cocoa trees must be encouraged to enhance pollination effectiveness and subsequent high fruit set. However, higher fruit abortion were recorded on cocoa trees with higher fruit set which, in the present study, were found on cocoa trees treated with rotten banana pseudostem and rotten cocoa pod husks. This phenomenon could be explained by the energy budget of the cocoa tree that determines its carrying capacity $[34,35]$. Since cocoa fruits contain up to 400 times more energy than flowers [36], more fruits set at a time could place greater demands on the energetic budget of the cocoa plant, disrupting its metabolism and manifesting as greater rates of fruit abortion [17,35,37]. High abortion of fruit set after the high levels of pollination could therefore decrease the initial benefit derived from increased pollination as suggested by [18]. [15] reported that the optimum level of pollination for the cocoa plant is $40 \%$ of the flowers produced. In the present study however, only $26 \%$ and $29 \%$, respectively of the original fruit set under rotten banana pseudostem and rotten cocoa pod husks were retained for fruit filling. On the other hand, there was $46 \%$ retention of fruits set on cocoa trees under the cocoa leaf litter. This implied that although cocoa leaf litter resulted in average increases in midges population and subsequently not too high levels of pollination, there was a significantly higher number of set fruits retained which could result in high cocoa pod yields. Consequently, in accordance with the observed trend, cocoa leaf litter should be considered as the most appropriate substrate for midges activity in cocoa for high yields.

\subsection{Ecological Significance of the Substrates on the Cocoa Farms}

Each of the substrates found on the farms had significance in the cocoa ecosystem as they all harboured the cocoa pollinators. Additionally, all the substrates could play roles in the supply of nutrients to the cocoa crop. The tropical cocoa tree has up to several leaf production cycles (rhythmic, discontinuous flushes) per year [38], and in Ghana cocoa leaf-litter production follows a definite cycle, with a peak in the dry season, August, November to February and through the wet season, March to July and September (Brew, unpublished). Several factors might contribute to their fall. These include fungal infections, raindrops, wind damage [39,40], insect injury, and physiological fall (result of higher rate of transpiretion) [41]. Some earlier studies also suggested that the pod husk may be the home of many genera of immature ceratopogonids [21,27]. However large amounts of cocoa pod husks left near growing cocoa trees conflicts with current cultural control of the black pod disease and therefore such residue should be removed and burnt. As regards the rotten banana pseudostem which supported the highest population of the midges, its continuous presence on the cocoa farm could be encouraged.

\subsection{Implications to Cocoa Production}

The results of the study suggest that by increasing the habitat-carrying capacity, the population density of Forcipomyia spp. is enhanced. Earlier workers have observed that habitat destruction has been a problem in the pollination of cacao, and that the removal of rotting substrate in which the pollinating midges undergo larval development, have resulted in yield reduction [19,42]. Consequently $[20,27]$ suggested placing banana and palm trunks, respectively, to encourage and maintain adequate pollinator forces. $[43,44]$ indicated that the presence of plantain/banana as an intercrop of the cocoa production system influenced the abundance of ceratopogonids. The accumulation of substrates which leads to higher population density of the midges under natural farm conditions could be an indirect approach to breeding of pollinators in cocoa production systems.

\section{REFERENCES}

[1] COCOBOD Report, 2012.

http://www.cocobod.gh/news_details10.php

[2] M. Asamoah and F. Baah, "Improving Research-Farmer Linkages: The Role of CRIG," 4th International Seminar on Cocoa-Pests and Diseases (INCOPED), Accra, 19-21 October 2003.

[3] C. Breisinger, X. Diao, S. Kolavalli and J. Thurlow, “The Role of Cocoa in Ghana's Future Development," Ghana Strategy Support Program (GSSP), Background Paper No. GSSP 0011, International Food Policy Research Institute, Accra, 2008.

[4] J. Gockowski, "The Analysis of Policies, Productivity and Agricultural Transformation in the Cocoa-Producing Rural Economies of West Africa,” STCP Technical Report Executive Summary, International Institute of Tropical Agriculture, IITA-Ghana, Accra, 2007.

[5] S. C. Harland, "Studies in Cacao. Part I. The Method of Pollination,” Annals of Applied Biology, Vol. 12, 1925, pp. 403-409.

[6] M. M. Bos, I Steffan-Dewenter, T. Tscharntke, "Shade Tree Management Affects Fruit Abortion, Insect Pests and Pathogens of Cacao," Agriculture, Ecosystems and Environment, Vol. 120, No. 2-4, 2007, pp. 201-205. doi:10.1016/j.agee.2006.09.004

[7] A. F. Posnette, "The Pollination of Cacao in the Gold Coast," Journal of Horticultural Science, Vol. 25, 1950, pp. 115-163

[8] P. F. Entwistle, "Pests of Cocoa," Longman, London. 
1972.

[9] T. Kaufman, "Ecology and Behaviour of Cocoa Pollinating Ceratopogonidae in Ghana, West Africa,” Environmental Entomology, Vol. 4, No. 2, 1975, pp. 347-351.

[10] C. Cilas, "Study of Natural Cacao Pollination in Togo and Its Implication for Production,” Proceedings of the 10th International Cocoa Research Conference, Santo Domingo, 17-23 May 1987, pp. 283-286.

[11] G. A. Ibrahim, "Effects of Insect Pollinators on Fruit Set of Cocoa Flowers," Proceedings of the International Cocoa Research Conference, Santo Domingo, 17-23 May 1987, pp. 303-306.

[12] A. M. Young, "The Chocolate Tree: A Natural History of Cacao,” Amazon and Co., 1994, p. 200.

[13] A. M. Klein, B. E. Vaissiere, J. H. Cane, I. Steffan-Dewenter, S. A. Cunningham, C. Kremen and T. Tscharntke, "Importance of Pollinators in Changing Landscapes for World Crops," Proceedings of the Royal Society of London, Vol. B274, 2007, pp. 303-313.

[14] A. M. Klein, S. A. Cunningham, M. Bos and I. SteffanDewenter, "Advances in Pollination Ecology from Tropical Plantation Crops,” Ecology, Vol. 89, No. 4, 2008, pp. 935-943. doi:10.1890/07-0088.1

[15] J. H. Groeneveld, T. Tscharntke, G. Moser and Y. Clough, "Experimental Evidence for Stronger Cacao Yield Limitation by Pollination than by Plant Resources," Perspectives in Plant Ecology, Evolution and Systematics, Vol. 12, No. 3, 2010, pp. 183-191. doi:10.1016/j.ppees.2010.02.005

[16] J. A. Winder and P. Silva, "Cacao Pollination: Microdiptera of Cacao Plantations and Some of Their Breeding Places,” Bulletin of Entomological Research, Vol. 61, No. 4, 1972, pp. 651-655. doi:10.1017/S0007485300047465

[17] A. G. Stephenson, "Flower and Fruit Abortion: Proximate Causes and Ultimate Functions," Annual Review of Ecology and Systematics, Vol. 12, 1981, pp 253-279. doi:10.1146/annurev.es.12.110181.001345

[18] M. M. Bos, D. Veddeler, A. K. Bogdanski, A.-M. Klein, T. Tscharntke, I. Steffan-Dewenter and J. M. Tylianakis, "Caveats to Quantifying Ecosystem Services: Fruit Abortion Blurs Benefits from Crop Pollination,” Ecological Applications, Vol. 17, No. 6, 2007, pp. 1841-1849. doi:10.1890/06-1763.1

[19] J. A. Winder, "Field Observations on Ceratopogonidae and Other Diptera: Nematocera Associated with Cocoa Flowers in Brazil," Bulletin of Entomological Research, Vol. 67, No. 1, 1977, pp. 57-63. doi:10.1017/S0007485300010890

[20] A. Ismail and A. G. Ibrahim, "The Potential for Ceratopogonid Midges as Insect Pollinators of Cocoa in Malaysia,” In: M. Y. Hussein and A. G. Ibrahim, Eds., Biological Control in the Tropics, Universiti Pertanian Malaysia, Serdang, 1986, pp. 471-484

[21] A. H. Brew, "Cocoa Pod Husk as a Breeding Substrate for Forcipomyia Midges and Related Species Which Pollinate Cocoa in Ghana,” Cocoa Growers Bulletin, No. 40, 1988, pp. 40-42.
[22] T. Kaufman, "Behavioral Biology of a Cocoa Pollinator, Forcipomyia inornatipennis (Diptera: Ceratopogonidae) in Ghana,” Journal of the Kansas Entomological Society, Vol. 47, No. 4, 1974, pp. 541-548.

[23] A. H. Brew, "Forcipomyia Midge Species Breed in Rotten Organic Substrates,” Report of Cocoa Research Institute of Ghana1982/83-1984, 1987.

[24] J. B. Hall and M. D. Swaine, "Distribution and Ecology of Vascular Plants in Tropical Rain Forest. Forest Vegetation in Ghana. Geobotany 1,’ Dr. W. Junk Publishers, The Hague, 1981.

[25] A. M. Young, “Cocoa Pollination,” Cocoa Growers’ Bulletin, Vol. 37, 1986, pp. 5-23.

[26] A. M. Young, "Effects of Shade over and Availability of Midge Breeding Sites on Pollinating Midge Populations and Fruit Set in Two Cocoa Farms," Journal of Applied Ecology, Vol. 18, No. 1, 1982, pp. 149-155. doi: $10.2307 / 2402485$

[27] W. S. Armbruster, "Multilevel Comparative Analysis of the Morphology, Function, and Evolution of Dalechampia Blossoms,” Ecology, Vol. 69, No. 6, 1988, pp. 1746-1761. doi:10.2307/1941153

[28] K. M. Olsen, "Pollination Effectiveness and Pollinator Importance in a Population of Heterotheca subaxillaris (Asteraceae),” Oecologia, Vol. 109, 1997, p. 114.

[29] J. N. Holland and D. L. DeAngelis, "Ecological and Evolutionary Conditions for Fruit Abortion to Regulate Pollinating Seed-Eaters and Increase Plant Reproduction," Theoretical Population Biology, Vol. 61, No. 3, 2002, pp. 251-263. doi:10.1006/tpbi.2001.1571

[30] O. D. Jennersten and H. Morse, “The Quality of Pollination by Diurnal and Nocturnal Insects Visiting Common Milkweed, Asclepias syriaca," American Midland Naturalist, Vol. 125, No. 1, 1991, pp. 18-28. doi: $10.2307 / 2426365$

[31] J. D. Thomson and B. A. Thomson, "Pollen Presentation and Viability Schedules in Animal-Pollinated Plants: Consequences for Reproductive Success,” In: R. Wyatt Ed., Ecology and Evolution of Plant Reproduction, Chapman and Hall, New York, 1992, pp. 1-24.

[32] K. H. Hasenstein and M. S. Zavada, "Auxin Modification of the Incompatibility Response in Theobroma cacao," Physiologia Plantarum, Vol. 112, No. 1, 2001, pp. 113118. doi:10.1034/j.1399-3054.2001.1120115.x

[33] A.-A. F. de Almeida and R. R. Valle, "Ecophysiology of the Cacao Tree," Brazilian Journal of Plant Physiology, Vol. 19, No. 4, 2007.

[34] F. A. Bazzaz, N. R. Chiariello, P. D. Coley and F. L. Pitelka, "Allocating Resources to Reproduction and Defense: New assessments of the Costs and Benefits of Allocation Patterns in Plants Are Relating Ecological Roles to Resource Use,” BioScience, Vol. 37, No. 1, 1987, pp 58-67. doi:10.2307/1310178

[35] A. O. Brown and J. N. McNeil, "Fruit Production in Crandberry (Ericaceae: Vaccinium macrocarpon): A BetHedging Strategy to Optimize Reproductive Effort," American Journal of Botany, Vol. 93, No. 6, 2006, pp. 
910-916. doi:10.3732/ajb.93.6.910

[36] R. R. Valle, A. A. F. De Almeida and R. M. O. Leite "Energy Costs of Flowering, Fruiting and Cherelle Wilt in Cacao," Tree Physiology, Vol. 6, No. 3, 1990, pp. 329336. doi:10.1093/treephys/6.3.329

[37] M. L. Stanton, J. K. Bereczky and H. D. Hasbrouck, "Pollination Thoroughness and Maternal Yield Regulation in Wild Radish, Raphanus raphanistrum (Brassicaceae)," Oecologia, Vol. 74, No. 1, 1987, pp. 68-76. doi:10.1007/BF00377347

[38] K. Mijayi, S. Walny, D. Silva and P. D. T. Alvim, "Longevity of Leaves of a Tropical Tree, Theobroma cacao, Grown under Shading, in Relation to Position within the Canopy and Time of Emergence,” New Phytologist, Vol. 135, No. 3, 1997, pp. 445-454. doi:10.1046/j.1469-8137.1997.00667.X

[39] P. de T. Alvim, “Cacao,” In: P. de T. Alvim and T. T. Kozlowsky, Eds., Ecophysiology of Tropical Crops, Academic Press, London, 1977, pp. 279-313.

[40] K. Miyaji and H. Tagawa, "Longevity and Productivity of Leaves of a Cultivated Annual, Glycine max Merrill. I. Longevity of Leaves in Relation to Density and Sowing
Time,” New Phytologist, Vol. 82, 1979, pp. 233-244.

[41] K. Miyaji, W. S. Silva and P. T. Alvim, "Longevity and Productivity of Leaves of Theobroma cacao L. in Relation to Their Position within the Canopy under Different Shading," Abstracts of the V International Congress of Ecology, Yokohama, 1990, p. 273.

[42] P. G. Kevan and P. P. Truman, "The Economic Impacts of Pollinator Declines: An Approach to Assessing the Consequences," Conservation Ecology, Vol. 5, No. 1, 2001, p. 8. http://www.consecol.org/vol5/iss1/art8/

[43] J. E. Elizondo and G. A. Enriquez, "Evaluation of 12 Different Types of Musaceae as Breeding Sites for the Cacao Pollinating Insects (Forcipomyia spp.) in Shade and Full Sun at La Lola, Costa Rica," Proceedings of the 10th International Cocoa Research Conference, Santo Domingo, 17-23 May 1987, pp. 297-302.

[44] E. A. Frimpong, B. Gemmill-Herren, I. Gordon and P. K. Kwapong, "Dynamics of Insect Pollinators as Influenced by Cocoa Production Systems in Ghana,” Journal of Pollination Ecology, Vol. 5, No. 10, 2011, pp. 74-80. 